\title{
Interdialytic Body Weight Gain, Anxiety, Fatigue and Quality of Life in Hemodialysis Patients During the COVID-19 Pandemic
}

\section{Gina Nurdina* and Dian Anggraeni}

Sekolah Tinggi Ilmu Keperawatan PPNI Jawa Barat, Bandung, Indonesia

\section{ORCID}

Gina Nurdina: https://orcid.org/0000-0003-0653-8066

Corresponding Author: Gina Nurdina; email:

ghina.nurdina@gmail.com

Published: 7 February 2022

Publishing services provided by Knowledge E

(c) Gina Nurdina and Dian Anggraeni. This article is distributed under the terms of the Creative Commons.

Attribution License, which permits unrestricted use and redistribution provided that the original author and source are credited.

Selection and Peer-review unde the responsibility of the IVCN Conference Committee.
Abstract. Hemodialysis patients are at a high risk of contracting COVID-19 and have a high risk of death when infected with COVID-19. During the pandemic, anxiety and fear have escalated, triggering more psychological disorders among hemodialysis patients, leading to depression and decreased quality of life. Therefore, the purpose of this study was to describe interdialytic body weight gain (IDWG), anxiety, fatigue and quality of life in hemodialysis patients during the COVID-19 pandemic. This was quantitative research with a descriptive approach and a survey design. 74 hemodialysis patients at various hemodialysis clinics in Bandung were recruited using consecutive sampling. The instruments used included the IDWG observation sheet, Beck Anxiety Inventory, the Fatigue Severity Scale, and KDQoL-SF36. Univariate analyses were conducted using frequency distribution. The mean IDWG was $5.35 \pm 5.21$, and 33 respondents (44\%) were in the light category. The mean score for fatigue was $40.37 \pm 16.99$, and 47 respondents (63\%) experienced fatigue. The mean anxiety score was $22.12 \pm 10.2$, and 30 respondents (40\%) were in the deficient category. Meanwhile, the highest average quality of life score was in the SF-12 mental health composite aspect, with $45.39 \pm 7.59$, and the lowest was in the burden of kidney disease aspect with an average value of $14.42 \pm 6.58$. Some respondents had mild IDWG, fatigue and anxiety levels, and some respondents had a poor quality of life.

Keywords: anxiety, fatigue, hemodialysis, IDWG, quality of life

\section{Introduction}

Hemodialysis (HD) is one of the most widely used renal replacement therapies for end-stage chronic kidney disease patients. The prevalence of chronic kidney disease globally is increasing and becoming a serious health problem by $13.4 \%$ and is ranked the 12th cause of death in the world, with a mortality rate of $31.7 \%$ over the last ten years [1]. The prevalence of chronic kidney disease in Indonesia aged 15 years is $2 \%$ per mil or around 499,800 people, and in 2018 , it increased by $3.8 \%$. Worldwide, an estimated 2 million people receive dialysis each year [2]. Indonesia, in recent years, has continued to increase the number of patients undergoing hemodialysis. Based on data from the Indonesian Renal Registry (2018), the number of patients actively undergoing 
HD in Indonesia is 198,575 people, and the highest number is in West Java with 48,599 patients and 37\% new patients from 2017 to 2018. In 2017 around 108,723 patients undergoing hemodialysis, in 2018, around 198,575 and in 2020, there were almost 235,822 patients and nearly 450 patients infected with COVID-19 [2]. This number will continue to increase every year.

Hemodialysis patients do dialysis for 3-4 hours and do it 2-3 times a week [3]. This activity will continue throughout his life. During the COVID-19 pandemic, some people are advised to stay at home, but hemodialysis patients must go to the hospital for regular dialysis. This can raise concerns about the transmission of the virus when the patient is on dialysis. Patients on hemodialysis may be at higher risk for infection with COVID-19 because of the many accompanying disease conditions [4]. Around 200,000 hemodialysis patients infected with COVID-19 are at risk of dying because complicated health procedures have left patients neglected [5]. Hemodialysis patients who are older and have comorbid conditions further increase the risk of disease transmission due to frequent repeated physical presence in health care facilities and the physical proximity of patients during hemodialysis. Increase sharply when they are infected with COVID-19 [6].

Before the COVID-19 Pandemic, hemodialysis patients experienced physical and emotional difficulties as they suffered from life-limiting illnesses. During the Pandemic, the anxiety and fear became more volatile, triggering more psychological disorders among hemodialysis patients, leading to depression or more severe mental disorders [4]. Complications of hemodialysis can cause discomfort, decreased quality of life, including physical, psychological, spiritual health, socioeconomic status and family dynamics. The psychological impact of hemodialysis is very complex and will affect physical, social and spiritual health. One of the psychological impacts caused is anxiety [7]. Anxiety significantly affects the mental and physical components of quality of life. Decreased quality of life is an increased risk of suicide in hemodialysis patients [8]. Patients undergoing dialysis also experience side effects of fatigue due to the uremia syndrome. The prevalence of fatigue in hemodialysis patients is $60-97 \%$. More than $70 \%$ of dialysis patients experience severe fatigue. Hemodialysis patients who have low levels of fatigue have a higher quality of life than those who have high levels of fatigue. Decreased quality of life can also be caused by an increase in IDWG of more than $3.5 \%$ of dry body weight, so that patients experience decreased urine output, cramps, fatigue, dizziness, edema, ascites, and shortness of breath which result in difficulty in performing physical activities such as walking, bending and moving the body [8][9][10]. Therefore, researchers are interested in knowing the description of Interdialytic Body 
Weight Gains (IDWG), Anxiety, Fatigue, and Quality of Life in Hemodialysis Patients in the New Normal Era of the COVID-19 Pandemic.

\section{Materials and Methods}

The type of research used is a quantitative research using descriptive methods. The research design used a survey design. This study aims to describe the description of IDWG, levels of anxiety, fatigue, and quality of life of hemodialysis patients. In addition, this research has conducted an ethical test with the number III/102/KEPKSLE/STIKEP/PPNI/JABAR/X/2021.

\subsection{Population and Research Sample}

The population of this study were patients undergoing hemodialysis at several hemodialysis clinics in Bandung. The patient is a member of Komunitas Pasien Cuci Darah Indonesia Jawa Barat (KPCDI West Java). Inclusion criteria were age 20 years, hemodialysis treatment for three months and awareness of compos mentis. The exclusion criteria were cognitive dysfunction or mental retardation-the sampling technique used consecutive sampling. The number of samples was calculated using G-Power Software Version 3.1.6 with $\times 2$ test, statistical test Variance: Difference from constant (one sample Case) and t-test assumptions, $=0.05$, effect size $=0.5$, power level $=0.80$. So the total sample to be recruited is 75 respondents.

\subsection{Data Collection Tool}

Data collection tools used in this study are as follows:

1. Questionnaires, used to collect data related to the characteristics of respondents, namely age, gender, occupation and length of time undergoing hemodialysis.

2. The patient's body weight was weighed routinely before and after HD. IDWG was measured by calculating the patient's weight after (post) HD in the first hemodialysis period (a measurement I). The patient's weight was weighed again before (pre) HD (measurement II) in the second hemodialysis period. Then calculate the difference between measurement II minus measurement I divided by measurement II multiplied by $100 \%$. The classification of IWG is divided into three groups, namely, light $(<4 \%)$, moderate $(4-6 \%)$ and severe $(>6 \%)$ [11]. 
3. Anxiety is measured by the Beck Anxiety Inventory questionnaire. The total score is calculated from 21 questions. Score 0-21 = low anxiety. Score 22-35 = moderate anxiety. A score of 36 and above = severe anxiety [12]. The researcher used the Indonesian version of the questionnaire. Researchers have tested the validity of 30 respondents with different results $(r=0.38)$ and an Alpha value of 0.80 .

4. The Fatigue Severity Scale instrument to measure the level of Fatigue. This questionnaire consists of nine statements that represent the level of Fatigue of the respondents [13]. The highest score was 63 , and the lowest was 9 . The researcher used the Indonesian version of the questionnaire. Researchers have tested the validity of 30 different respondents obtained an r-value of 0.326 and an Alpha value of 0.76 .

5. Kidney Disease Quality of Life Short Form 36 (KDQoL-SF36) instrument measured quality of life. This questionnaire consists of 36 questions with five aspects: a list of symptoms/problems, effects of kidney disease, the burden of kidney disease, components of physical health, and mental health components [14]. The researcher used the Indonesian version of the questionnaire. Researchers have tested the validity of 30 different respondents obtained an r-value of 0.388 and an Alpha value of 0.79 .

\subsection{Data Collection Procedure}

The research begins with the researcher taking care of all the necessary permits. After obtaining permission, the researcher will identify the research respondents. Researchers joined the West Java KCPDI Whatsapp Group. The researcher explained to the respondents about the objectives and benefits of the research. Then asked his willingness to be a respondent and agreed to the informed consent. Respondents were included in the research Whatsapp group. Respondents were asked to fill out a questionnaire via the Google form link that the researcher provided. The Google form provides questionnaires on respondent characteristics, IDWG observation sheets, Beck Anxiety Inventory, the Fatigue Severity Scale and Kidney Disease Quality of Life Short Form 36 (KDQoL-SF36). After that, the researchers collected the results of the study for further data processing. 
TABLE 1: Demographic characteristics of Hemodialysis Patients New Normal Era of the COVID-19 Pandemic

\begin{tabular}{|c|c|}
\hline Variabel & Total Poputalation $(\mathrm{N}=75)$ \\
\hline $\begin{array}{l}\text { Age years (mean } \pm \text { SD) Range Gen- } \\
\text { der Male Female Education Junior } \\
\text { High School Senior High School Col- } \\
\text { lege Length of hemodialysis years } \\
\text { (mean } \pm \text { SD) Range } \leq 1 \text { years } 1-3 \text { years } \\
4-6 \text { years } \geq 7 \text { years }\end{array}$ & 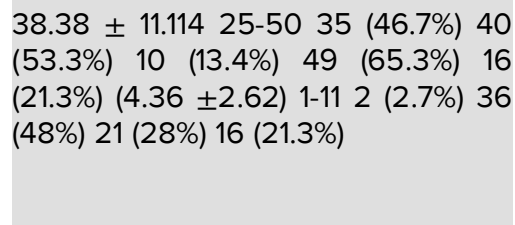 \\
\hline
\end{tabular}

TABLE 2: Frequency Distribution of IDWG, Fatigue Level, Anxiety Level and Quality of Life Hemodialysis Patients New Normal Era of the COVID-19 Pandemic

\begin{tabular}{|c|c|c|}
\hline & $\begin{array}{l}\text { Frequency } \\
(\mathrm{N}=75)\end{array}$ & $\begin{array}{l}\text { Percent } \\
\text { (\%) }\end{array}$ \\
\hline $\begin{array}{l}\text { Interdialytic Body Weight } \\
\text { Gains (IDWG) Mild }(<4 \%) \\
\text { Medium (4-6\%) Severe }(6 \%)\end{array}$ & 332715 & 443620 \\
\hline $\begin{array}{l}\text { Fatigue Level Fatigue Not } \\
\text { fatigue }\end{array}$ & 4728 & 6337 \\
\hline $\begin{array}{l}\text { Anxiety Level Very low Moder- } \\
\text { ate Severe }\end{array}$ & 302718 & 403624 \\
\hline Quality of Life Good Poor & 3045 & 4060 \\
\hline
\end{tabular}

\subsection{Data analysis}

Data analysis used the IBM SPSS Statistics version 24 application. All data were processed in a quantitative descriptive manner used to report the results in a frequency distribution, percentage (\%), mean, median, drinking and maximum of each characteristic.

\section{Result}

The study was conducted on hemodialysis patients who are members of KCPDI Jawa Barat. Data collection was carried out in May 2021 with a total sample of 75 respondents. The results of the study are presented in the form of tables and narratives as follows:

Based on table 1 above, the average age is 38.38 ( $S D=11,114)$. Female gender is more dominant with a percentage of $53.3 \%$ of respondents. For education history, most respondents (65.3\%) graduated from high school/equivalent and underwent hemodialysis an average of $4.17(\mathrm{SD}=2.68)$ mostly in the range of 1 to 3 years $(61.8 \%)$.

Based on table II, it is known that the most IDWG in the light category were 33 respondents (44\%) and the least in the severe category were 15 respondents (20\%). Most of the respondents experienced fatigue, namely 47 respondents (63\%). Meanwhile, the highest anxiety level is in the deficient category as many as 30 respondents (40\%). 
TABLE 3: Mean, Median, Min, Max and Varience Values of IDWG, Fatigue, Anxiety and Quality of Life for Hemodialysis Patients New Normal Era of the COVID-19 Pandemic

\begin{tabular}{|c|c|c|c|c|c|}
\hline & Mean \pm SD & Median & Min & Max & Variance \\
\hline $\begin{array}{l}\text { Interdialytic Body Weight Gains } \\
\text { (IDWG) }\end{array}$ & $5.35 \pm 5.21$ & 4.24 & 0.00 & 29.12 & 27.14 \\
\hline Fatigue & $40.37 \pm 16.99$ & 42.00 & 9 & 63 & 288.75 \\
\hline Anxiety & $22.12 \pm 10.2$ & 12.01 & 2 & 45 & 144.26 \\
\hline Quality of Life & $207.15 \pm 68.54$ & 204.33 & 176.99 & 244.18 & 260.64 \\
\hline Symptom/problem list & $66.64 \pm 7.21$ & 66.67 & 50.00 & 85.42 & 51.92 \\
\hline Effects of kidney disease & $44.00 \pm 10.31$ & 43.75 & 28.13 & 65.63 & 106.25 \\
\hline Burden of kidney disease & $14.42 \pm 6.58$ & 12.50 & 6.25 & 25.00 & 43.26 \\
\hline $\begin{array}{l}\text { SF-12 Physical health } \\
\text { composite }\end{array}$ & $36.73 \pm 5.54$ & 37.51 & 23.21 & 47.22 & 30.70 \\
\hline SF-12 Mental health composite & $45.39 \pm 7.59$ & 44.75 & 29.75 & 60.18 & 57.64 \\
\hline
\end{tabular}

The lowest anxiety level in the severe category was 18 respondents (24\%). Most of the respondents experienced poor quality of life as many as 45 respondents (60\%).

Based on table III, it is known that the average IDWG value is $5.35 \pm 5.21$, the minimum value is 0.00 , the maximum value is 29.12 , the median is 4.24 , and the variance is 27.14 . The average score for fatigue is $40.37 \pm 16.99$, and the minimum value is 9 , the maximum value is 63 , the median is 42.00 , and the variance is 288.75 . The average score for anxiety is $22.12 \pm 10.2$, the minimum score is 2 , the maximum score is 45 , the median is 112.01 , and the variance is 144.26 . Meanwhile, the highest average Quality of life score on the SF-12 mental health composite aspect was $45.39 \pm 7.59$ with a minimum score of 29.75, a maximum value of 60.18 , a median of 72.97 and a variance of 5.64. The burden of kidney disease aspect got the lowest score with an average value of $14.42 \pm 6.58$, a minimum score of 6.25 , a maximum value of 25.00 , a median of 12.50 and a variance of 43.26 .

Based on table IV, it is known that the mild IDWG category is mainly experienced by women as many as 20 respondents, high school senior education level and undergoing hemodialysis for 1 to 3 years. At the fatigue level, women also experience more fatigue than men, namely 24 respondents, high school senior education levels and undergoing hemodialysis for 1-3 years experience the most fatigue. A shallow level of anxiety was experienced by women as many as 16 respondents. Respondents most experienced fatigue with a high school education level of 28 respondents, and the worst quality of life was experienced mainly by female respondents, amounting to 24 respondents. There are also much poor quality of life in high school senior education and undergoing hemodialysis for $1-3$ years. 
TABLE 4: Cross tabulation of respondents' characteristics with IDGW, fatigue, anxiety, and quality of life

\begin{tabular}{|c|c|c|c|c|c|c|}
\hline & & \multicolumn{3}{|c|}{$\begin{array}{l}\text { Interdialytic Body } \\
\text { Weight Gains (IDWG) }\end{array}$} & \multicolumn{2}{|c|}{ Fatigue Level } \\
\hline & & Mild & Medium & Severe & $\begin{array}{l}\text { Not } \\
\text { Fatigue }\end{array}$ & Fatigue \\
\hline \multirow[t]{3}{*}{ Gender } & Male & 13 & 14 & 8 & 12 & 23 \\
\hline & Female & 20 & 13 & 7 & 16 & 24 \\
\hline & Total & 33 & 27 & 15 & 28 & 47 \\
\hline \multirow[t]{4}{*}{ Education } & $\begin{array}{l}\text { Junior } \\
\text { High } \\
\text { School }\end{array}$ & 4 & 4 & 2 & 3 & 7 \\
\hline & $\begin{array}{l}\text { Senior } \\
\text { High } \\
\text { School }\end{array}$ & 24 & 16 & 9 & 21 & 28 \\
\hline & College & 5 & 7 & 4 & 4 & 12 \\
\hline & Total & 33 & 27 & 15 & 28 & 47 \\
\hline \multirow{5}{*}{$\begin{array}{l}\text { Length of } \\
\text { hemodialysis }\end{array}$} & $\leq$ yyears & 1 & 1 & 0 & 0 & 2 \\
\hline & $1-3$ years & 18 & 14 & 4 & 16 & 20 \\
\hline & $4-6$ years & 7 & 8 & 6 & 7 & 14 \\
\hline & $\geq 7$ years & 7 & 4 & 5 & 5 & 11 \\
\hline & Total & 33 & 27 & 15 & 28 & 47 \\
\hline
\end{tabular}

\begin{tabular}{|l|l|l|l|l|}
\hline Anxiety Level & & \multicolumn{2}{c}{ Quality of Life } \\
\hline Very low & Moderate & Severe & Poor & Good \\
\hline 14 & 14 & 7 & 21 & 14 \\
16 & 13 & 11 & 24 & 16 \\
\hline 30 & 27 & 18 & 45 & 30 \\
5 & 3 & 2 & 9 & 1 \\
\hline 21 & 16 & 12 & 27 & 22 \\
\hline 4 & 8 & 4 & 9 & 7 \\
\hline 30 & 27 & 18 & 45 & 30 \\
\hline 0 & 1 & 1 & 1 & 1 \\
\hline 20 & 10 & 6 & 25 & 11 \\
\hline 5 & 10 & 6 & 13 & 8 \\
\hline 5 & 10 & 6 & 6 & 10 \\
\hline 30 & 27 & 18 & 45 & 30 \\
\hline
\end{tabular}

IDWG is associated with patient compliance behavior in undergoing hemodialysis for a long time[15]. Hemodialysis patients generally have different lengths of time undergoing hemodialysis and weight gain between the two different hemodialyses. In this study, it was found that more respondents were included in the mild category IDWG (<4\%) as many as 33 respondents (44\%); this is by Jalalzadeh's (2021) study which stated that most of the respondents had IDWG $<4 \%[16]$. The average value of IDWG in this study is $5.35 \pm 5.21$. The results of this study are higher than the results of Maimani's (2021) study, which obtained a mean value of $4.1 \pm 1.9$. The IDWG value in this study is still above the IDWG value that the body of $<3 \%$ can tolerate. The Japanese Society for Dialysis Therapy stated that patients with \%IDWG $>6.0 \%$ had a higher risk of death than those with \%IDWG between $2.0 \%$ and $4.0 \%$ [17]. Studying IDWG targets is particularly important because excessive IDWG has been associated with clinically unfavorable conditions and is considered an independent predictor of all-cause and cardiovascular mortality in patients undergoing long-term HD[18][15].

Meanwhile, when viewed from a gender perspective, men have higher IDWG values than women; previous studies stated that interdialytic weight gain was directly related to body weight. The total water in a man's body makes up $60 \%$ of his body weight, while the total water in a woman's body makes up $50 \%$ of his body weight. Total body water will provide weight gain that increases faster than the addition caused by calories. Related to this, in hemodialysis patients, the weight gain between two dialysis times in men is higher than in women [17][19][20]. 
Many factors influence IDWG, such as environment, nutrition, patient behavior, physiological and psychological factors[21]. The ability of hemodialysis patients to maintain a normal IDWG is influenced by patient compliance in maintaining weight, self-awareness not to neglect or forget, being supported by family, and strong expectations of getting a better quality of life (19). In this study, the average value of fatigue was $40.37 \pm 16.99$, with the most categories, namely 47 respondents (63\%) experiencing fatigue. This is my previous research; namely, most of them experienced fatigue with a mean value of $41.18(\mathrm{SD}=17.11)[21]$.

Fatigue arises due to various factors, including physiological factors (anemia, malnutrition, uremia, hyperparathyroidism, inflammation that arise from chronic kidney failure. Psychological factors including stress, depression, anxiety can trigger fatigue. The stress response enters the central nervous system; then the hypothalamus is released the corticotrophin hormone-releasing factor, which will stimulate the sympathetic nervous system to release norepinephrine, a vasoconstrictor result in smooth muscle contraction[22][10].

In this study, the average Anxiety score was $22.12 \pm 10.2$, with the highest category being as deficient as $40 \%$. Anxiety is highly dependent on the patient's sociodemographic data such as age, gender, and level of education [8]. Among our respondents, women have a higher number of experiencing severe anxiety. This is supported by research by Mosleh (2020) that women have significantly higher levels of anxiety than men $(P<0.05)$ levels of anxiety than men $(P<0.05)$. This finding is consistent with many findings of previous studies of patients on hemodialysis. Several studies have shown that women tend to be more anxious with more suicidal thoughts than men. Women are more likely to develop anxiety, whereas men are more likely to show symptoms of depression [21].

Patients with the chronic disease tend to experience a decreased quality of life. These changes were caused by various factors, both internal and external. Evaluation of the quality of life of patients with chronic diseases, especially chronic kidney disease, is essential because the poor quality of life will affect the outcome of the disease and increase the risk of patient morbidity and mortality [23].

The measurement of the patient's quality of life showed that the symptom/problem list aspect was at the highest average $(66.64 \pm 7.21)$ compared to other aspects. Based on the list of symptoms in the instrument, the majority answered "slightly disturbed" or "not at all disturbed." In line with the research conducted by Cohen et al. (2019) that the symptom/problem list aspect has a higher mean value than the other aspects. This raises the possibility that the list of symptoms queried in the instrument may need to be 
refreshed to account for changes in their long-standing dialysis experience [24][7]. The results of this study were that most of the respondents had undergone hemodialysis for more than three years so that patients had adapted to various symptoms. However, based on research findings, some symptoms are pretty disturbing, namely dry skin and itchy skin. Another study stated that hemodialysis patients experienced mild and severe itching, but there was no significant relationship between the incidence of dry and itchy skin and the duration of hemodialysis. Dry skin is caused by uremia, which affects corneocyte maturation and a decrease in water content in the epidermis of the skin, a decrease in the volume of atrophy of the sebaceous glands and sweat glands so that the skin becomes dry and itchy [25].

The burden of kidney disease in this study had the lowest mean value. Based on the question items of the instrument, the majority of respondents felt that kidney disease interfered with their lives too much. So that the patient feels frustrated and becomes a burden to his family. HD patients have limited participation in the life and feel dependent on treatment. They feel that they are not understood by others and fail to live up to expectations. This affects the patient's self-esteem related to changes in roles, relationships, identity, and meaning in life, so kidney disease becomes a heavy burden for them [26].

Another study states that HD patients feel guilty because they depend on and burden their spouses or children. HD patients think they disappoint their children because they run out of energy to spend time with them. Meanwhile, HD patients who are the breadwinners cannot support their families and become a burden on the family. Especially during the COVID-19 pandemic, the economy is experiencing difficulties due to government policies to carry out social distancing. Another burden of kidney disease is the amount of time that must be spent on treating kidney disease. The amount of time spent doing dialysis sessions for 3-4 hours a week three times makes all their energy and strength drained to experience fatigue [27].

\section{Conclusion}

Based on the results of this study, it was found that some hemodialysis respondents during the COVID-19 pandemic were in the mild IDWG category, most experienced fatigue, most experienced deficient anxiety levels, and most experienced poor quality of life. 


\section{References}

[1] Hill NR, Fatoba ST, Oke JL, et al. Global prevalence of chronic kidney disease - A systematic review and meta-analysis. PLoS One. 2016;1-18.

[2] IR Resgistry. 11th report of Indonesian renal registry. 2018. Available from: https://www.indonesianrenalregistry.org/data/IRR 2018.pdf

[3] Black Joyce H, Jane Hokanson, Hawks. Keperawatan medikal bedah: Manajemen klinis untuk hasil yang diharapkan. $8^{\text {th }}$ ed. Jakarta: Elsevier, 2014.

[4] Patel M, Kute V, Prasad N, et al. COVID 19 and hemodialysis anxiety. Indian Journal of Nephrology. 2020; Vol. 30(3): 174-175.

[5] Wang R, Liao C, He H, et al. COVID-19 in hemodialysis patients: A report of 5 cases. American Journal of Kidney Diseases. 2020;76(1):141-3.

[6] Ikizler TA. COVID-19 and dialysis units: What do we know now and what should we do? American Journal of Kidney Diseases. 2020;76( July):1-3.

[7] Shdaifat EA, Yaccob JL, Razak BT, Manaf KR. Quality of life of caregivers and patients undergoing haemodialysis at Ministry of Health, Jordan. 2012.

[8] Isık Ulusoy O, Kal S. Relationship among coping strategies, quality of life, and anxiety and depressive disorders in hemodialysis patients. Therapeutic Apheresis and Dialysis. 2020;24(2):189-196. doi: https://doi.org/10.1111/1744-9987.12914

[9] Argawal R, et al. Assesment and management of hypertension in patients on dialysis. J. Am. Soc. Nephrol. 2014;25(8):1630-1646. doi: https://doi.org/10.1681/ASN.2013060601

[10] Artom M, et al. Fatigue in advanced kidney disease. Kidney International. 2014;86(3):1-9. doi: https://doi.org/10.1038/ki.2014.86

[11] Kozier S, Erb B, Berman G, Snyder A. Fundamental of nursing: Concepts, process and practice. New Jersey: Pearson Education; 2004.

[12] Carmin C, Raymond LO. Assessment of anxiety in older adults. Acta Medica Indonesiana. 2010:45-60. doi: 10.1016/B978-0-12-374961-1.10002-8

[13] Butarbutar DT. Uji reliabilitas dan validitas fatigue severity scale versi bahasa Indonesia pada dokter residen rsup dr. 2014.

[14] Supriyadi R, Rakhima F, Gondodiputro RS, Darmawan G. Validity and reliability of the Indonesian version of kidney disease quality of life (KDQOL-36) questionnaire in hemodialysis patients at Hasan Sadikin Hospital, Bandung, Indonesia. Acta Medica Indonesiana. 2019;51(4):318-323. 
[15] Kahraman A, et al. Impact of interdialytic weight gain (IDWG) on nutritional parameters, cardiovascular risk factors and quality of life in hemodialysis patients. BANTAO J. 2015;13(1):25-33. doi: 10.1515/bj-2015-0006

[16] Jalalzadeh M, Mousavinasab S, Villavicencio C, Aameish M, Chaudhari S, Baumstein D. Consequences of interdialytic weight gain among hemodialysis patients. Cureus. 2021;13(5):8-9. doi: 10.7759/cureus.15013

[17] Al Maimani Y, Elias F, Al Salmi A, Aboshakra A, Alla MA, Hannawi S. Interdialytic weight gain in hemodialysis patients: Worse hospital admissions and intradialytic hypotension. Open Journal of Nephrology (OJNEPH). 2021;11(2):156-170. doi: 10.4236/ojneph.2021.112013

[18] Jalalzadeh M, Mohammadi R, Mirzamohammadi F, Ghadiani MH. Prevalence of metabolic syndrome in a hemodialysis population. Iranian Journal of Kidney Diseases. 2011;5(4):248-254.

[19] Bayhakki B, Hasneli Y. Hubungan lama menjalani hemodialisis dengan inter-dialytic weight gain (IDWG) pada pasien hemodialisis. Jurnal Keperawatan Padjadjaran. 2018;5(3):242-248. doi: 10.24198/jkp.v5i3.646

[20] Kimmel PL, et al. Interdialytic weight gain and survival in hemodialysis patients: Effects of duration of ESRD and diabetes mellitus. Kidney International. 2000;57(3):1141-1151. doi: 10.1046/j.1523-1755.2000.00941.x

[21] Mosleh H, Alenezi M, Al johani S, Alsani A, Fairaq G, Bedaiwi R. Prevalence and factors of anxiety and depression in chronic kidney disease patients undergoing hemodialysis: A cross-sectional single-center study in Saudi Arabia. Cureus. 2020;12(1):1-11. doi: 10.7759/cureus.6668

[22] Letchmi S, et al. Fatigue experienced by patients receiving maintenance dialysis in hemodialysis units. Nursing \& Health Sciences. 2011;13(1):60-64. doi: 10.1111/j.14422018.2011.00579.x

[23] Marthoenis M, et al. Quality of life, depression, and anxiety of patients undergoing hemodialysis: Significant role of acceptance of the illness.

The International Journal of Psychiatry in Medicine. 2021;56(1):40-50. doi: 10.1177/0091217420913382

[24] Cohen DE, Lee A, Sibbel S, Benner D, Brunelli SM, Tentori F. Correction to: Use of the KDQOL-36TM for assessment of health-related quality of life among dialysis patients in the United States. BMC Nephrology. 2019;20(1):1-9. doi: 10.1186/s12882-019-1630-5

[25] Toruan ENAL. Pengaruh lotion OAT terhadap sensasi gatal pada pasien hemodialisa yang mengalami pruritus di RS kota medan. 2019. Available from: http://repositori.usu.ac.id/handle/123456789/28836. 
[26] Borg T, Verdonk, Jong-Camerik P, Abma M. How to relate to dialysis patients' fatigue - Perspectives of dialysis nurses and renal health professionals: A qualitative study. International Journal of Nursing Studies. 2021;117:10388.

[27] Jacobson J, et al. Patient perspectives on the meaning and impact of fatigue in hemodialysis: A systematic review and thematic analysis of qualitative studies. American Journal of Kidney Diseases. 2019;74(2):179-192. doi: 10.1053/j.ajkd.2019.01.034 